\title{
MÓDULO DEPORTIVO UNIVERSITARIO. CAMPUS DE SOMOSAGUAS. UNIVERSIDAD COMPLUTENSE DE MADRID
}

\author{
(MODULE FOR SPORTS AT THE SOMOSAGUAS CAMPUS. COMPLUTENSE \\ UNIVERSITY, MADRID)
}

Carlos García Tolosana, Arquitecto

Fecha de recepción: $20-11-97$

ESPAÑA

\begin{abstract}
RESUMEN
En el presente articulo se detalla la solución adoptada para la construcción de un edificio deportivo universitario, desde premisas de simplicidad y economia.
\end{abstract}

De su funcionamiento es reseñable su concepción en un único volumen que compatibiliza el entrenamiento deportivo, en condiciones de máximo aprovechamiento de la pista deportiva $y$ el deporte espectáculo, que se posibilita constituyendo el nivel de entrada como galeria-mirador, y con el concurso de graderios telescópicos que se recogen bajo las galerias longitudinales.

De su sistema constructivo, hay que anotar el carácter de "vistos" de todos los elementos e instalaciones que intervienen en la edificación, de forma que su función se enmarca, de forma expresa, en la geometria general.

\section{SUMMARY}

A university stadium built upon premisses of economy and simplicity.

About its functionality it can be reported that one single volume makes compatible sports training, with a top organization of the ground, and sports as a public show, which can be achieved by designing the entrance level as a balcony, with tiers of seats beneath the longitudinal galleries.

About its constructive system it can be pointed out that all elements used in its construction are "uncovered", in such a way their function confers expressivity to their geometrical aspect.

\section{Descripción arquitectónica}

El edificio de que se trata es un contenedor, formado por un único volumen, en el que se desarrolla la actividad deportiva principal y las complementarias que se pretenden.

El área deportiva propiamente dicha, se sitúa deprimida en relación al terreno circundante, de forma que, en condiciones de espectáculo, el área superior se configura como zona de público en forma de corredor-mirador perimetral.

Por su parte, el espacio deportivo se plantea a nivel inferior $y$ permite la disposición de tres pistas de baloncesto transversales para entrenamiento, que pueden individualizarse mediante cortinas compartimentadoras.
En condiciones de espectáculo, los graderios móviles, alojados bajo las galerias laterales, que se proyectan en voladizo, permitirán recibir a un total de setecientos veinte espectadores sentados.

Planta O (Nivel - 3,30)

En este nivel se sitúa el área deportiva, que incluye espacio suficiente para alojar los cajones de los graderíos móviles $y$ un paso perimetral que permite acceder a las instalaciones que se reciben en el muro circundante. En la zona de Levante se situan las entradas desde el patio de servicio, los almacenes de material deportivo que atienden a la pista, la sala de máquinas, dos vestuarios para las personas con movilidad reducida y dos gimnasios de musculación y calentamiento. 
En el área Oeste se sitúa el control de pista, el centro médico y un área para las asociaciones deportivas.

\section{Planta I (Nivel $+0,00)$}

Resuelve el espacio de público y en él se ubican dos pastillas de edificación, una, al Este, en la que se sitúan los vestuarios, la información y el bar y, otra, al Oeste, con los aseos para el público, que cumplimentan el Reglamento de Espectáculo y dependencias auxiliares.

De los vestuarios, cabe decir que se plantean cuatro módulos idénticos con cortavistas, vestuario propiamente dicho y zona higiénica, que comporta la existencia de área de lavabos, WC y duchas colectivas.

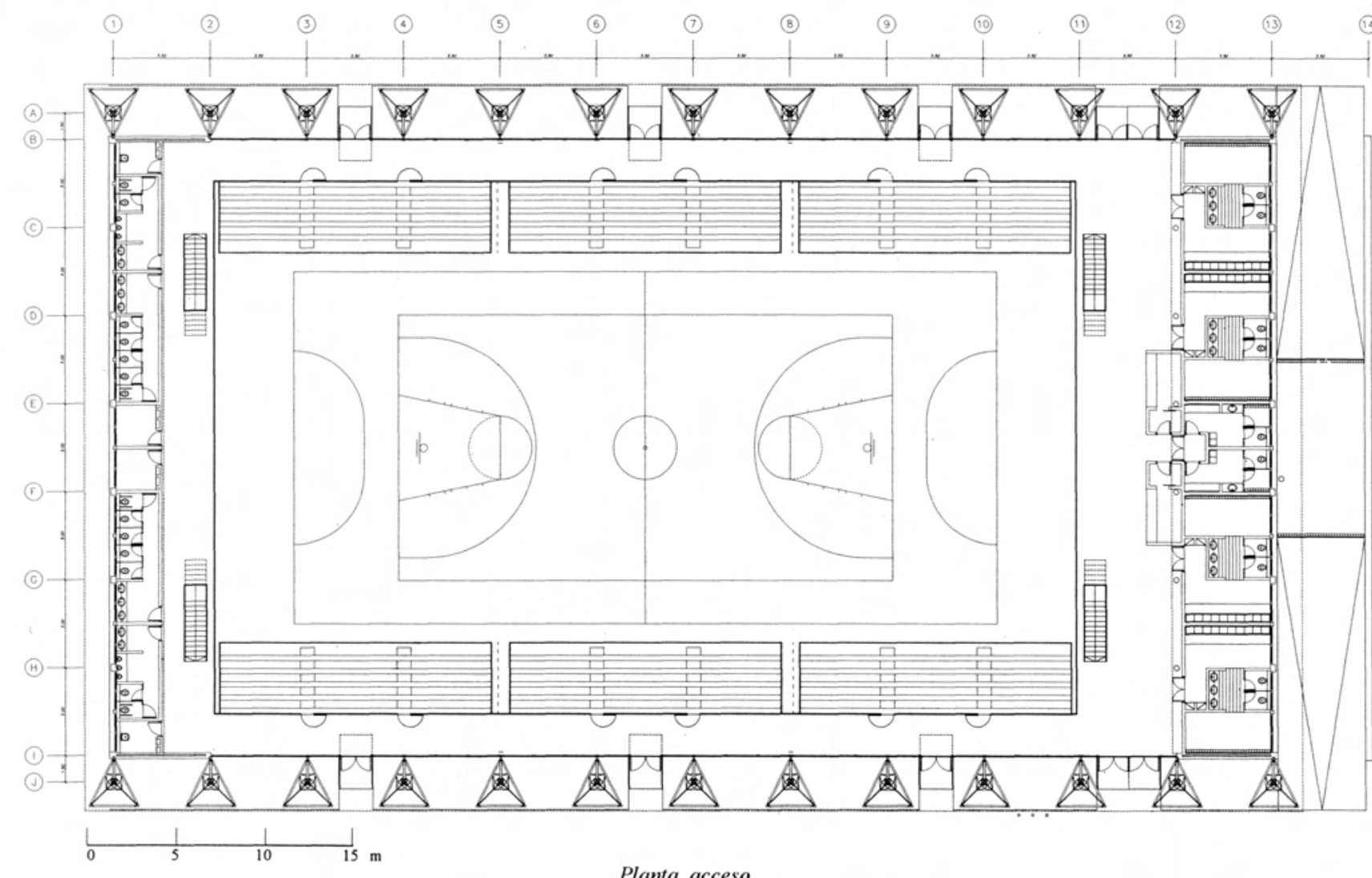

Planta acceso.

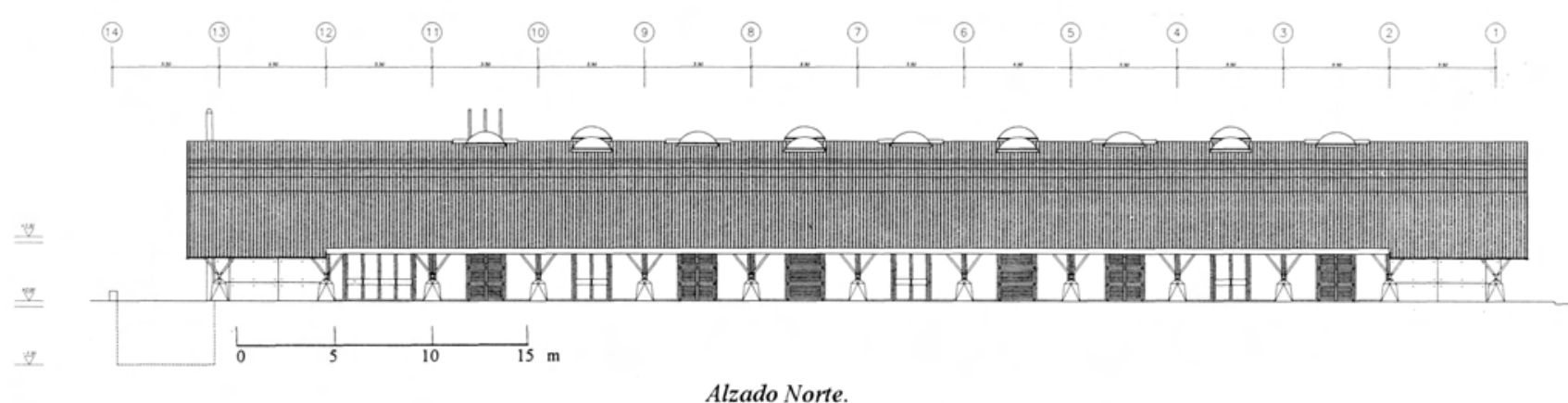

Alzado Norte.

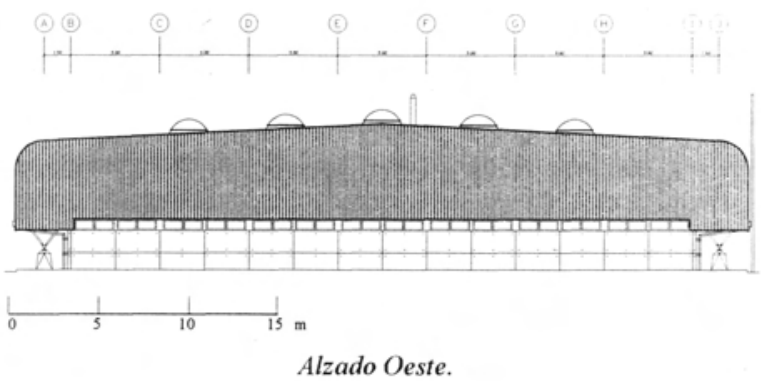

Alzado Oeste.

(c) Consejo Superior de Investigaciones Científicas Licencia Creative Commons 3.0 España (by-nc)

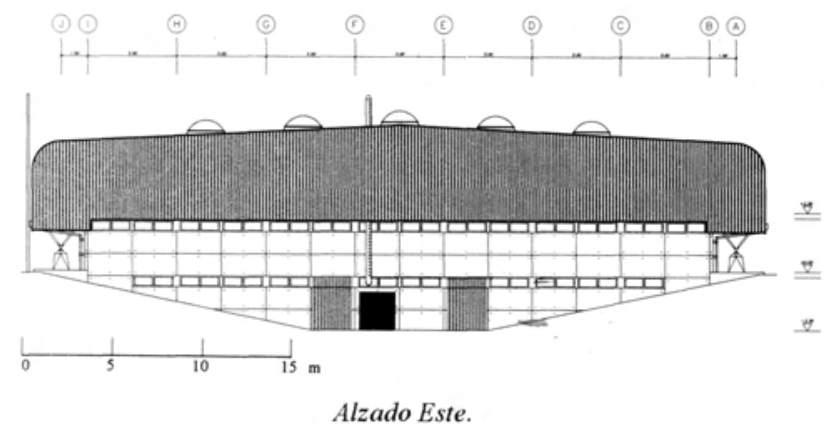

http://informesdelaconstruccion.revistas.csic.es 
La comunicación interior entre las plantas citadas se resuelve mediante cuatro escaleras, las cuales se disponen simétricamente.

En el exterior, y a Levante, el edificio resuelve un patio de servicio, al que se accede desde rampas dispuestas enfrentadas, que da paso, directamente, al nivel de pista.

Se trata, en definitiva, de un esquema de gran simplicidad, resuelto de forma que la depresión adoptada para la pista permite minimizar el volumen exterior que, por otra parte, se plantea con criterios de máxima contundencia.
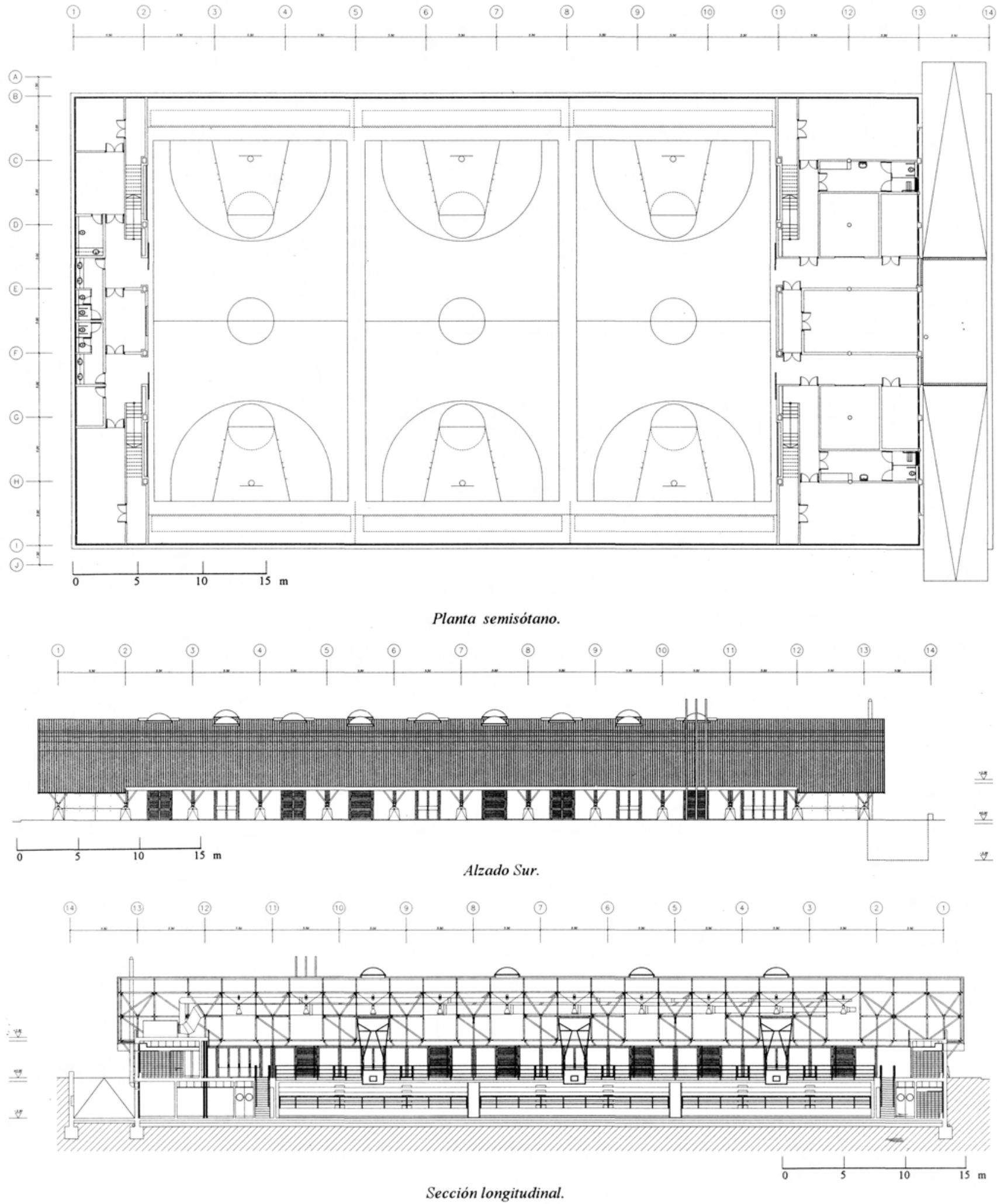

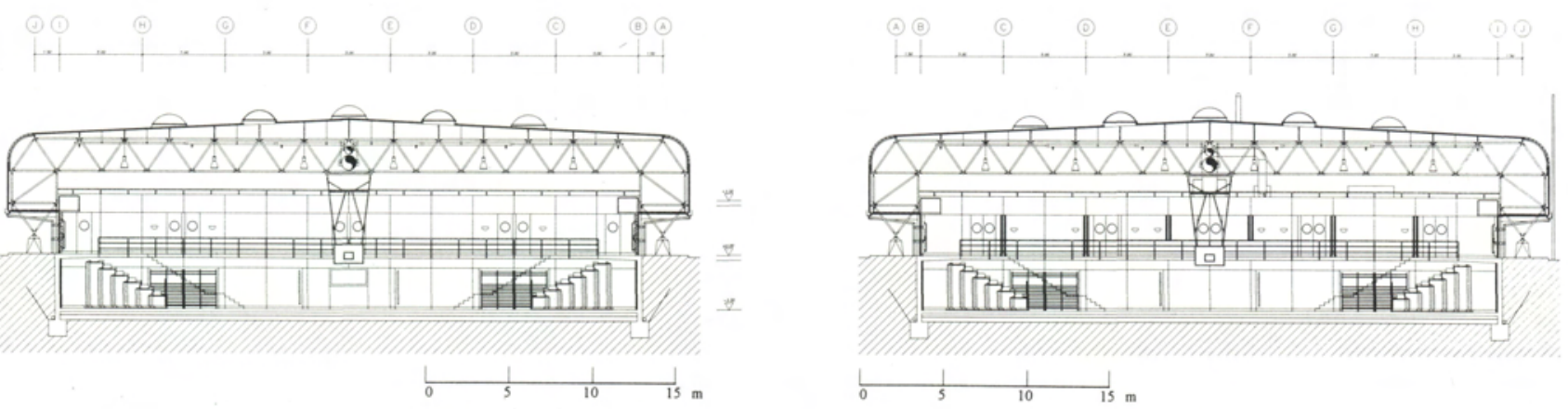

Secciones transversales.

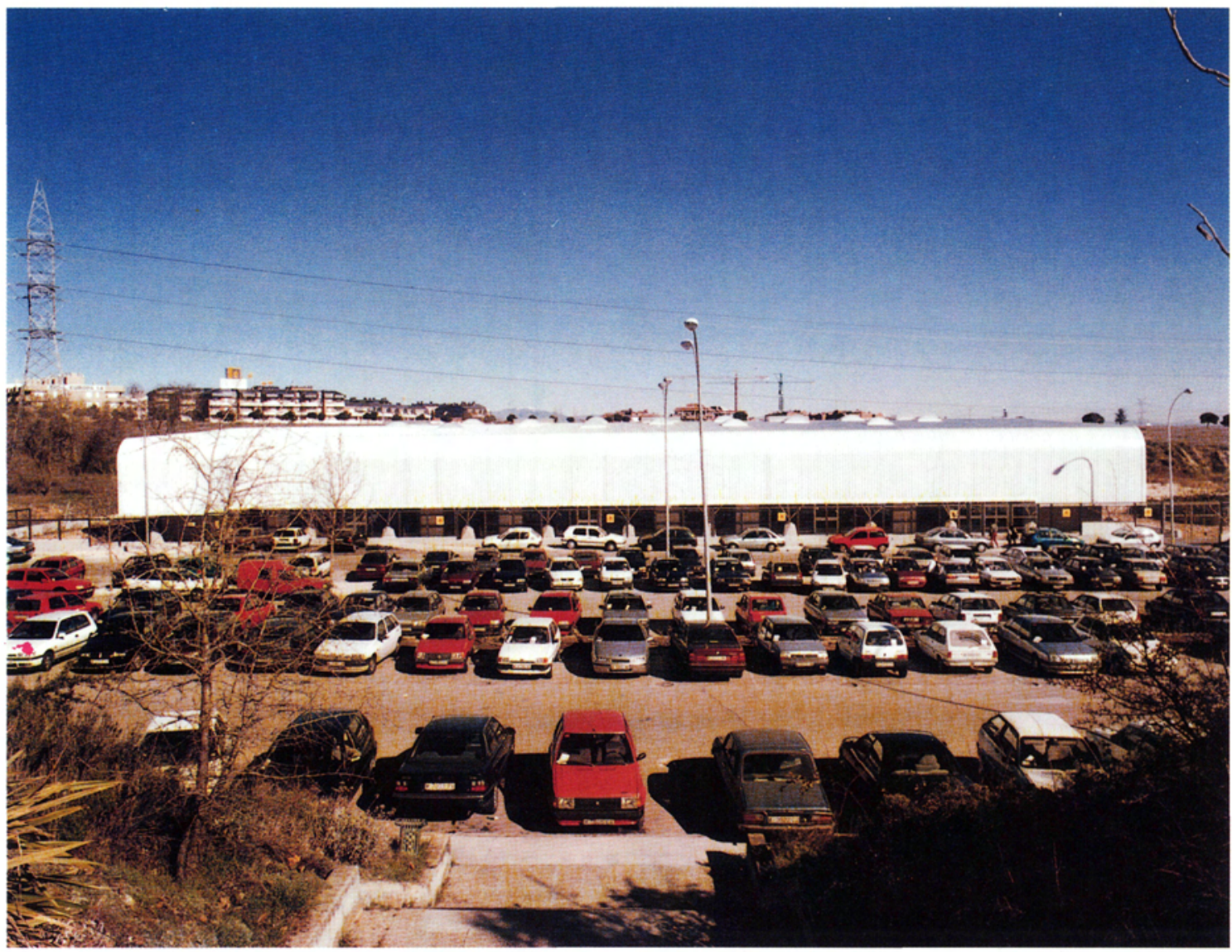

Vista general.

\section{Descripción constructiva}

La cimentación se diseñó atendiendo a las recomendaciones de la correspondiente campaña geotécnica suscrita por Geotecniay Cimientos, S.A. (Geocisa), la cual, por encargo de la Universidad Complutense de Madrid, realizó cuatro sondeos mecánicos y cuatro ensayos de penetración dinámica Borro.

Los sondeos se realizaron a rotación, con extracción continua de testigo mediante sonda Neptuno 2.000, que permite, también, la ejecución de los ensayos de penetración dinámica tipo Borro.
Dichos sondeos dieron lugar a los resultados siguientes:

$\begin{array}{llll}\text { Sondeo S1 } & \text { Longitud : } 12,95 \mathrm{~m} & \text { SPT 7 } & \text { TP 2 } \\ \text { Sondeo S2 } & \text { Longitud : } 11,50 \mathrm{~m} & \text { SPT 6 } & \text { TP 3 } \\ \text { Sondeo S3 } & \text { Longitud : } 13,80 \mathrm{~m} & \text { SPT 7 } & \text { TP 1 } \\ \text { Sondeo S4 } & \text { Longitud : } 12,80 \mathrm{~m} & \text { SPT 6 } & \text { TP 2 }\end{array}$

Se confirmó la presencia de nivel freático a $7,30 \mathrm{~m} \mathrm{y}$ a $8,50 \mathrm{~m}$ de profundidad con relación a la superficie del terreno, lo que se traduce en $6,70 . \mathrm{m}$ de profundidad en relación con la rasante de la calle.

Además, se realizaron en laboratorio ensayos de 

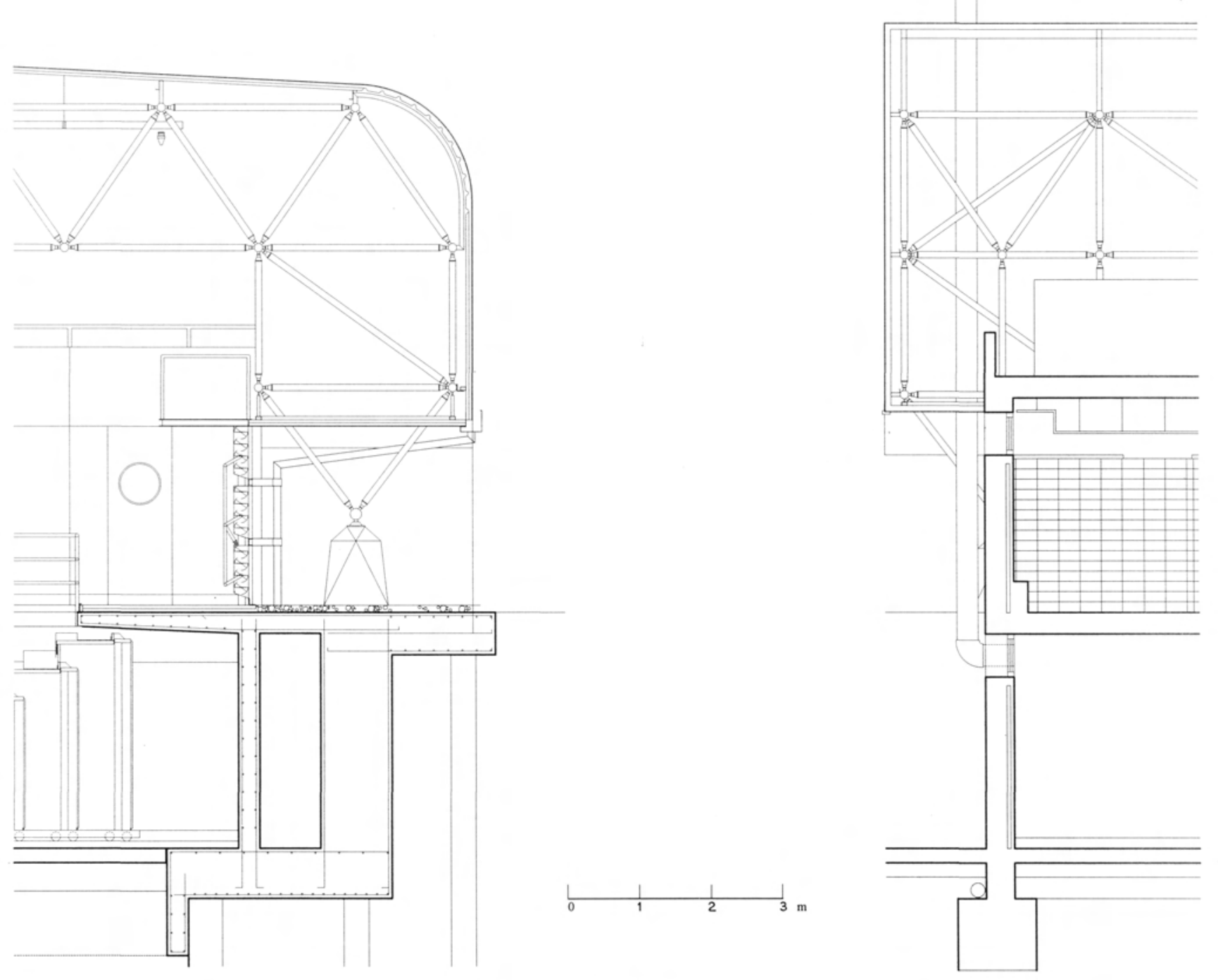

Secciones constructivas.
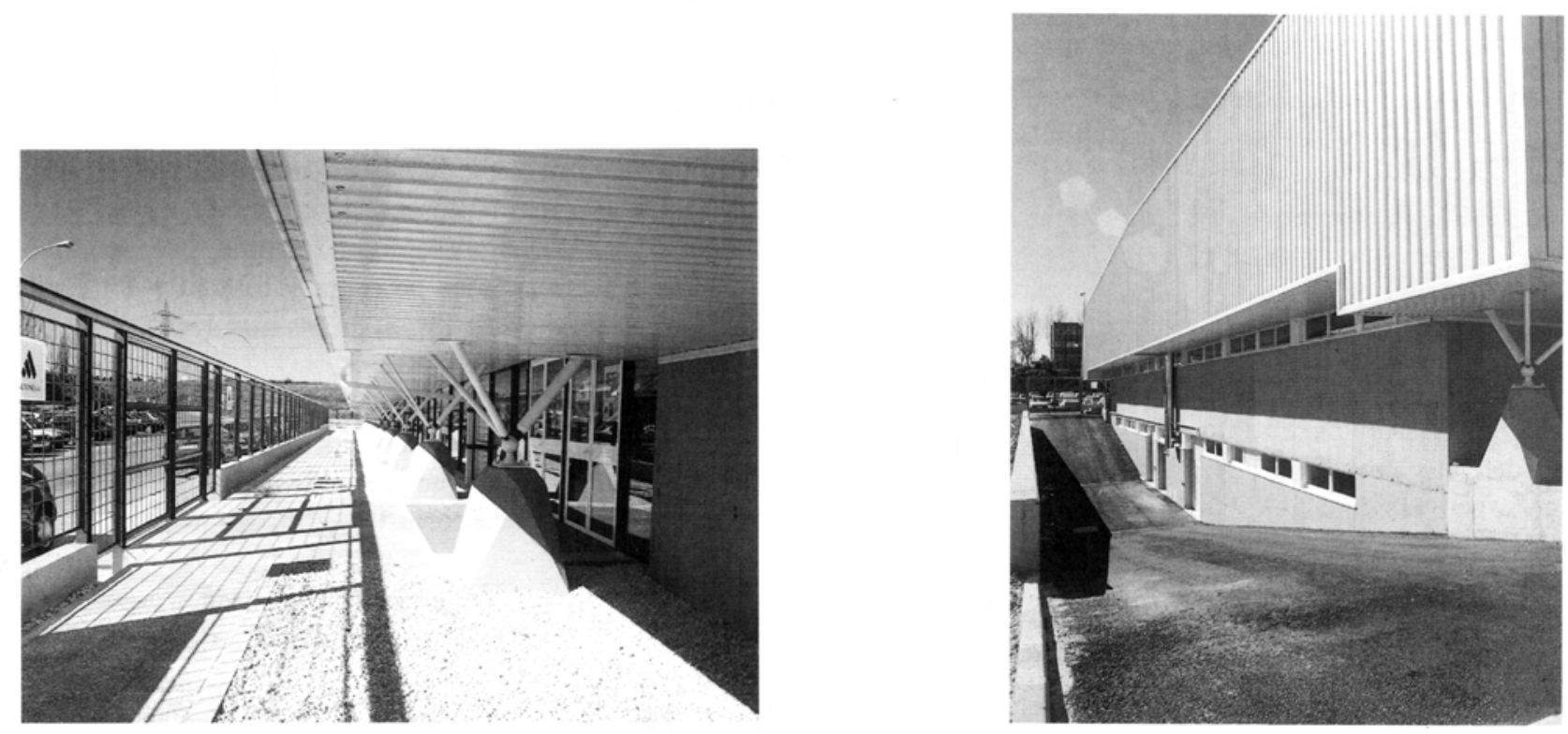

Vistas exteriores.

(c) Consejo Superior de Investigaciones Científicas Licencia Creative Commons 3.0 España (by-nc) 

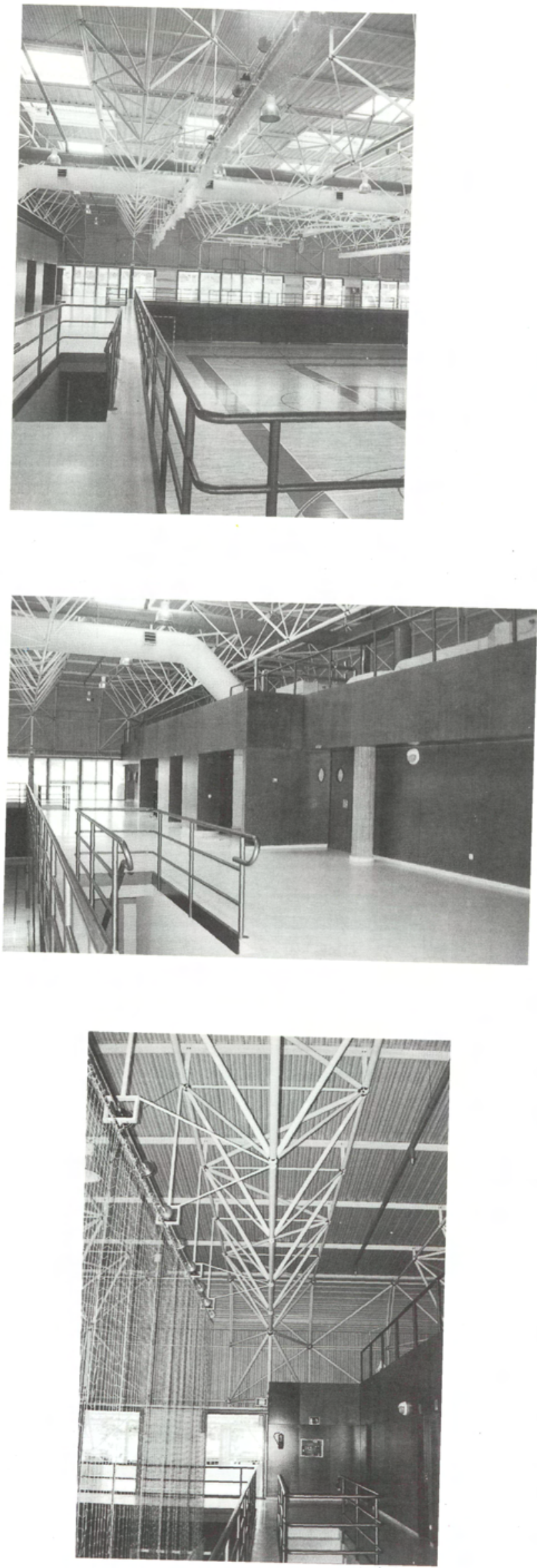

Vistas interiores.


identificación: Granulometría y Límites de Atterberg; de estado: Densidad seca y Humedad natural; de resistencia: Compresión simple; y químicos: Sulfatos solubles y Agresividad del agua

De acuerdo con todo ello, se determinó el carácter geológicodelazona, que puede definirse como "Facies Intermedias" o "Peñuelas", que representa la transición de la "Facies Madrid", en la que predominan los materiales arcósicos, medios a finos (arenas de miga y toscos) y $1^{\text {a "Facies }}$ Central", en la que predominan los materiales terciarios, con presencia habitual de yesos.

En este caso se da, además, un importante espesor de rellenos antrópicos, que apoyan sobre los materiales arcósicos, arenas arcillosas y arcillas arenosas.

Los cuatro sondeos realizados confirmaron la presencia de rellenos, con potencias comprendidas entre 10 y $11 \mathrm{~m}$.

En cuanto a la configuración de la zona, puede decirse que presenta la morfología típica de apilamiento de vertidos sobre la pendiente de un antiguo barranco. 
De acuerdo con los perfiles geotécnicos realizados por Geocisa, se consideraron dos niveles diferenciados: el primero, correspondiente a los materiales de vertido y el inferior, formado por las arenas y las arcillas arenosas. Los rellenos, a su vez, están formados por dos capas. En la más superficial, de un espesor comprendido entre 2 y $5 \mathrm{~m}$, muy heterogénea, conviven escombros y suelos. La más inferior, también de relleno, se configura en base a suelos granulares.

El nivel profundo corresponde al terreno natural, que está constituido por arenas tosquizas y tosco, siendo su techo para los distintos sondeos el que a continuación se cita, al igual que el que corresponde a los ensayos de penetración realizados:

$\begin{array}{lll}\text { Sondeo } \mathrm{S} 1 & >10,00 \mathrm{~m} & \text { Penetración } \mathrm{P}>10,00 \mathrm{~m} \\ \text { Sondeo S2 } & >1,60 \mathrm{~m} & \text { Penetración P2 }>9,00 \mathrm{~m} \\ \text { Sondeo S3 }>11,00 \mathrm{~m} & \text { Penetración P3 }>1,50 \mathrm{~m} \\ \text { Sondeo S4 }>8,20 \mathrm{~m} & \text { Penetración P4 }>8,00 \mathrm{~m}\end{array}$

En definitiva, cabe decir que se confirmó la existencia de rellenos superficiales constituidos por escombros y suelos, y una capa inferior de rellenos, formados por suelos arenolimosos y areno-arcillosos procedentes de las excavaciones en las cercanías, sobre formaciones detríticas. El espesor de estos rellenos alcanza profundidades de 10-11 m, siendo nula su competencia o aptitud como apoyo para las cimentaciones directas.
Bajo los rellenos indicados se comprobó la existencia de un suelo de edad miocena, constituido por materiales detríticos de naturaleza areno-arcillosa de gran compacidad, que pueden admitir tensiones de 3,0 a $3,5 \mathrm{~kg} / \mathrm{cm}^{2}$.

De acuerdo con esto, el Estudio Geotécnico, recomendó como cimentación más apropiada la profunda, mediante pilotes empotrados de 3 a $4 \mathrm{~m}$ en la capa inferior.

En cuanto a la solera de apoyo de las pistas deportivas, se recomendó una sustitución del terreno, de modo que se aporte una capa compactada de $1,50 \mathrm{~m}$ como mínimo.

De acuerdo con ello, el proceso constructivo propuesto, se concreta como sigue:

$1^{\circ}$ Excavación y retirada del terreno hasta una profundidad de $1,50 \mathrm{~m}$ por debajo de la cota de la solera de arranque del edificio

$2^{\circ}$ Compactación de la base de asiento hasta alcanzar, al menos, el 95\% del Proctor Normal.

$3^{\circ}$ Rellenode $1,50 \mathrm{~m}$ en toda la superficie mediante un sue10 "adecuado" del tipo terraplén, de los que se definen en el PG-3 del MOPU con un CBR $\geq 10$

Este relleno deberá construirse por tongadas no mayores

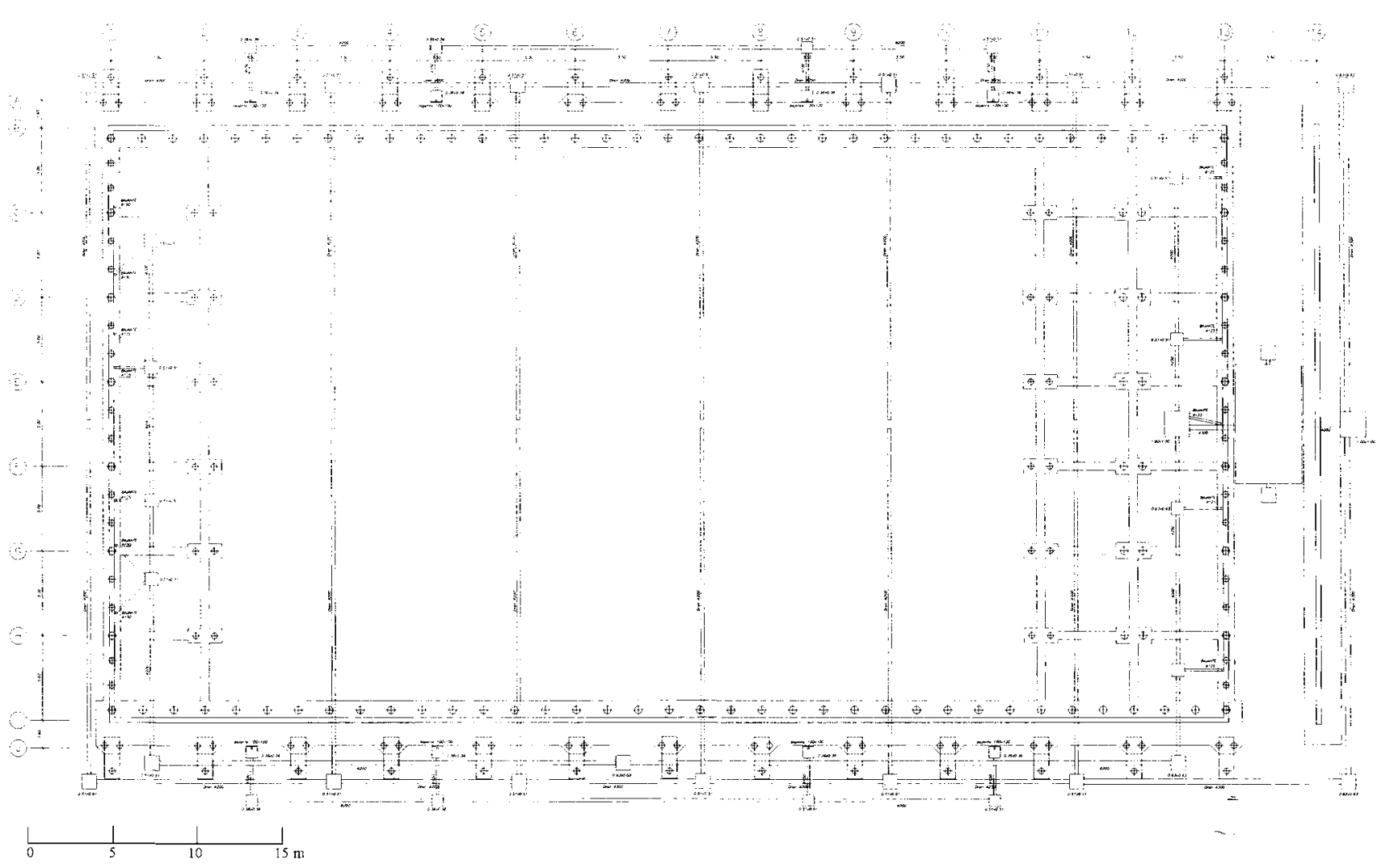


de $30 \mathrm{~cm}$ con un grado de compactación del $100 \%$ del ensayo Proctor Normal

$4^{\circ}$ Ejecución del pilotaje, mediante pilotes excavados con hélice continua y hormigonado in situ, de D-35 y D-45, admitiéndose las cargas que a continuación se relacionan:

$\begin{array}{llll}\text { Empotramiento } & 3,00 \mathrm{~m} & \text { Empotramiento } & 4,00 \mathrm{~m} \\ \text { D-35 cm } & 24 \mathrm{t} & \text { D-35 cm } & 28 \mathrm{t} \\ \text { D-45 cm } & 36 \mathrm{t} & \text { D-45 cm } & 40 \mathrm{t}\end{array}$

De acuerdo con todo lo expuesto anteriormente, la cimentación profunda de la edificación se llevó a cabo mediante pilotes excavados con hélice continua y hormigonados in situ, empotrados cuatro metros en la capa profunda de suelo natural mioceno de arenas tosquizas y tosco.

Debido a la existencia de nivel freático en las proximidades, puesta de manifiesto en el Estudio Geotécnico, se previó el entubado de un $40 \%$ del total, en previsión de presencia de agua.

Los pilotes se remataron con encepados arriostrados en las dos direcciones, de acuerdo con las recomendaciones del Estudio Geotécnico.
Especial atención se prestó al diseño de la cimentación de los muros, dado que éstos trasladan a los pilotes momentos flectores que es preciso minimizar. Es por ello por lo que se dispusieron los encepados con talones que utilizan el peso del terreno circundante.

La cimentación en los muros se construyó de forma que se generan puntos fuertes, formados por dos pilotes D-35 y un pilote $\mathrm{D}-45$, sobre los que cabalga el encepado continuo, que se refuerza con un talón que se aprovecha del empuje pasivo del terreno.

La solera se construyó sobre la sustitución del terreno recomendada por el Estudio Geotécnico y una vez que la compactación hubo alcanzado valores de $100 \%$ del Proctor Normal. Sobre la capa del terreno sustituido se dispuso una capa granular de $20 \mathrm{~cm}$ de espesor, una lámina de polietileno, una barrera de poliestireno extrusionado de $4 \mathrm{~cm}$ de espesor y una solera de hormigón $\mathrm{H}-175$ de $20 \mathrm{~cm}$ de espesor, armada con una retícula de $15 \times 15 \mathrm{~cm}$, con D-12 AEH-400 N

En previsión de una posible subida del nivel freático, y teniendo en cuenta que el espacio deportivo se solucionó con una tarima deportiva, se dispuso una importante red de drenaje formada por tuberías de PVC, dispuestas en malla, en el nivel más bajo de la excavación, previéndose, además, la posibilidad de realizar, en su día, pozos de recogida y achique, si ello fuera necesario.

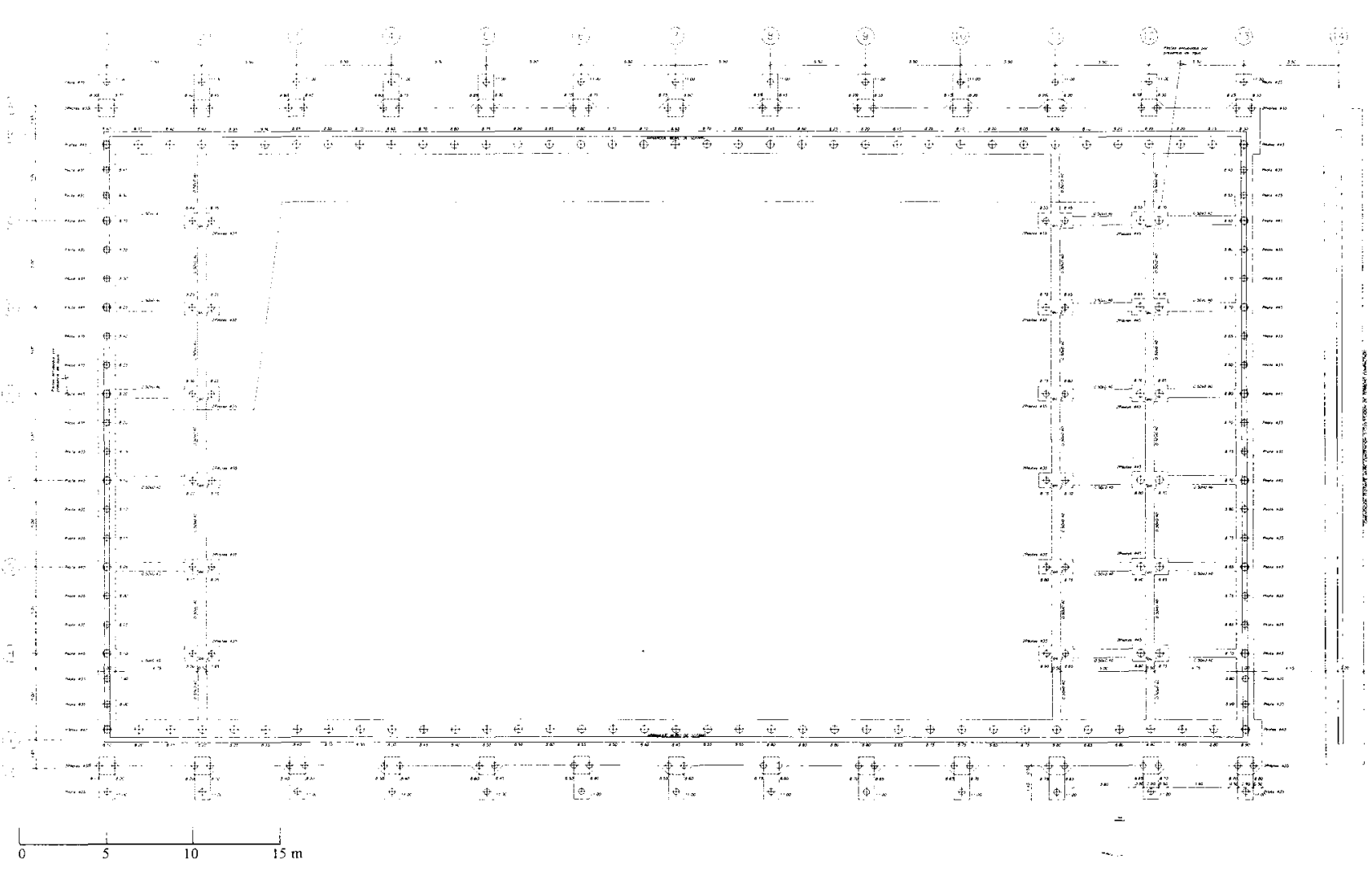

Planta de cimentación. 

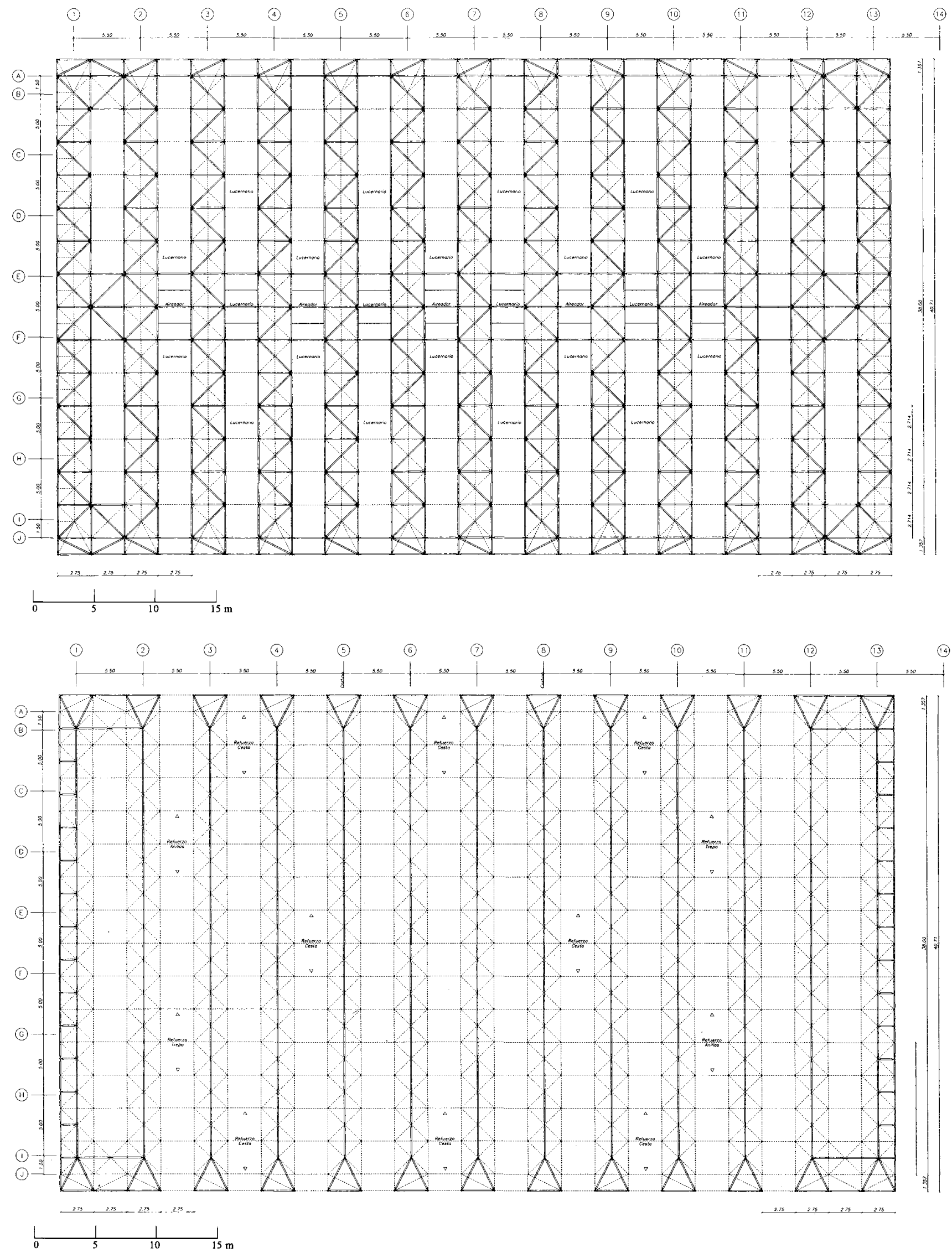

Estructura espacial (cordones superior e inferior).

La estructura se resolvió trabajando independientemente la obra convencional y la estructura espacial que configura exteriormente la edificación, salvando la totalidad de la luz del pabellón.
La estructura convencional se diseñó en hormigón H-175, formando un entramado de soportes y vigas que se remata y delimita con los muros de fachada y que se completa con forjados pretensados. 
Los soportes se diseñaron apoyados en una trama de $5,50 \times 5,00 \mathrm{~m}$, siendo de sección circular, y con tratamiento de superficie aquéllos que quedan vistos.

Las vigas se construyeron planas y embebidas en el canto del forjado, formando pórticos de simple y doble crujia.

Todo este conjunto, al igual que los muros de contención del perímetro y las losas en voladizo de los corredores, se construyó en hormigón armado.

Puede resumirse, en definitiva, que se construyó una cubeta de HA, soportada desde los pilotes, que se remata en una losa volada que conforma los andadores y en cuyos testeros se disponen una simple crujia, en el Oeste, y una doble crujía, en el Este, que trabajan, junto con los muros de fachada, también de HA, armando la totalidad del conjunto.

En los testeros, las crujías citadas albergan las dependencias señaladas con anterioridad en la descripción arquitectónica.

Vinculados a la parte superior de la cubeta, se trabajan los apoyos de la estructura de cubierta, que, desde los pilotes, alcanza el nivel del terreno para mostrarse en forma de punta de diamante y, desde este único punto de apoyo, se resuelve la estructura espacial que salva el espacio a cubrir, discriminando líneas resistentes secuenciales, que se arriostran en el centro y en los extremos del vano.

Dicha estructura se soluciona con esferas huecas y barras tubulares, con terminales de acoplamiento y con embellecedores que ocultan las tuercas móviles y las fijas, formando alineaciones sucesivas con semioctaedros yuxtapuestos.

Respecto a los materiales proyectados y a sus acabados, en el exterior e interior de la edificación se ha seguido el criterio de restringir su número, para permitir una lectura rápida y sencilla de las situaciones constructivas y para minimizar la conservación y el mantenimiento del Módulo Deportivo.

Exteriormente, el edificio se cierra, tanto en fachada como en cubierta, con un panel in situ de doble chapa de acero prelacada con aislamiento termoacústico interior, que se curva en el encuentro continuidad fachada - cubierta, y que se remata en un canalón longitudinal que evita la cortina de agua que se generaría en otro caso. La chapa interior se previó perforada, a fin de aumentar la absorción acustica del recinto, adecuando, en lo posible, la acústica del local.

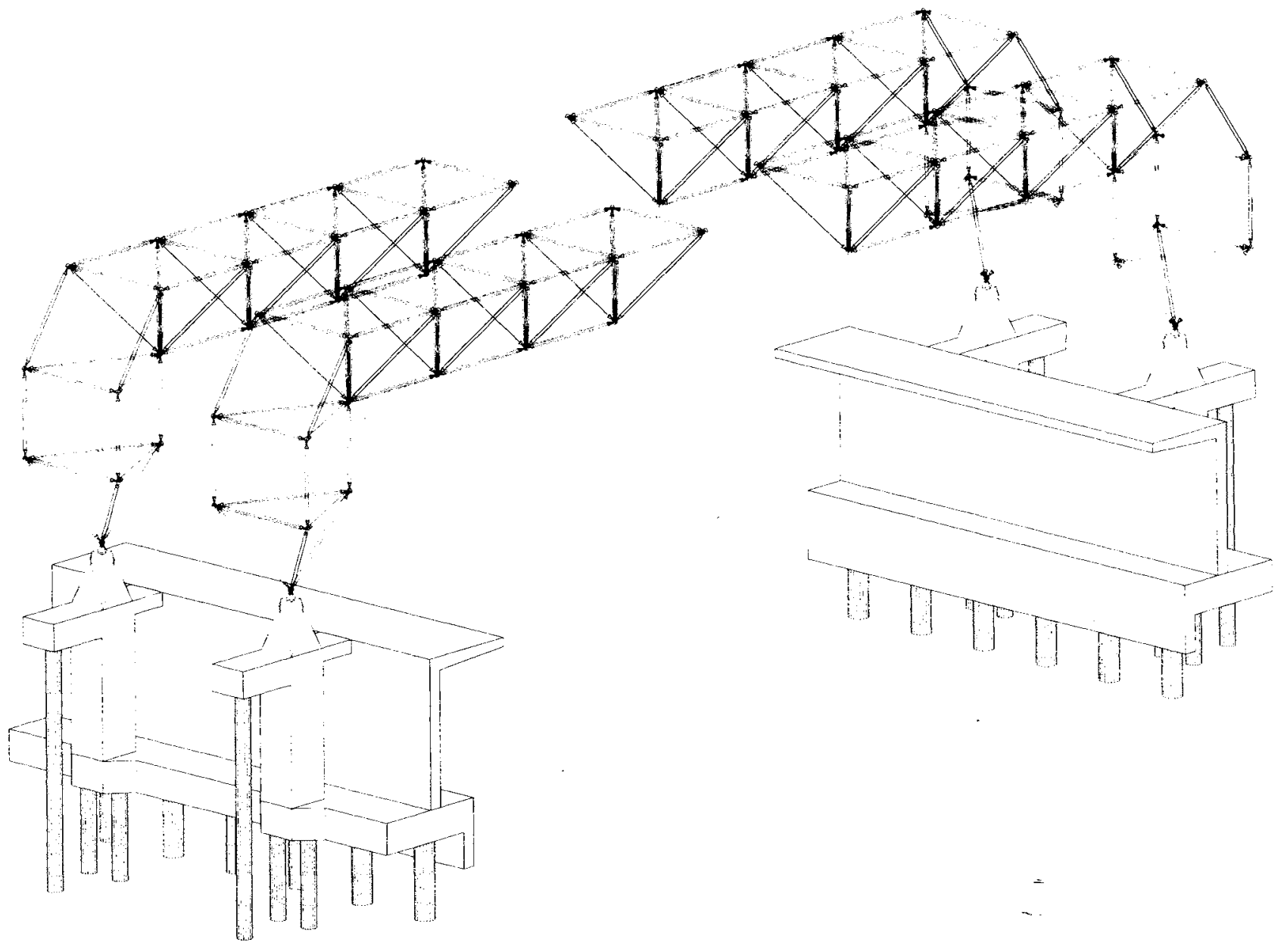


E1 encuentro de cubierta y fachada se resuelve desde criterios de total continuidad. De esta forma, la fachada se curva para pasar a ser cubierta y después, otra vez, para volver a ser fachada.

Desligados de la cáscara de fachada-cubierta se plantean los muros cortinas del Norte y del Sur que delimitan los andadores, que se solucionan con perfiles laminados en $H E B$, trabajando en voladizo desde la cubeta de HA inferior.

Los testeros edificados por debajo y por encima de la rasante se resuelven, en su totalidad, con hormigón, confiriendo estabilidad al conjunto de la estructura de cubierta, que les traslada los esfuerzos horizontales de viento que la solicitan.

En el interior, todos los frentes al área deportiva se diseñan en tablero DM, barnizado en su color, tratándose los interiores de los vestuarios, almacenes, gimnasios, etc., en forma tradicional.

Las condiciones térmicas de la edificación se estudiaron para minimizar el gasto, dada la importancia económica del mantenimiento y de la explotación del edificio. La producción de agua caliente (calefacción y A.C.S.) se confía a calderas alimentadas por gas natural.

Los niveles de iluminación artificial son superiores a 800 lux, para permitir las retransmisiones de TV, presentando distintas posibilidades de uso, para adecuarse a las distintas circunstancias de utilización de los espacios. Se hadotado, además, al edificio, de alumbradode señalización y de emergencia, de redes de telefonía interior y megafonía.
La detección y defensa contra el fuego, puertas de evacuación y de emergencia, sistemas activos, etc., se han diseñado cumpliendo con la vigente normativa española.

La ventilación se resuelve planteando, primero, un sistema de aireación natural, con entradas de aire en fachada y exultores en cubierta, que garantizan, además, la salida conducida del humo en caso de incendio. Dicho esquema se completa con la incorporación de un sistema mecánico de termoventilación, fundamentado en la disposición de climatizadores sobre el cuerpode vestuarios, que conducen el aire tratado mediante una doble red de conductos, una, en la que el aire circula a baja velocidad, enviándolo en forma de flujo laminar horizontal y, otra, de alta velocidad, que dirige el aire, en forma de chorro, hacia el laminar horizontal anterior, mediante boquillas inductivas, generando, asi, las correspondientes turbulencias, que conducen el aire hasta los niveles inferiores, evitando la estratificación del aire caliente en los niveles superiores.

La urbanización se ha limitado a la adecuación del entorno más próximo a la edificación, quedando pendiente la mejora de los espacios aledaños. Igualmente, queda pendiente la posible construcción de un módulo similar en el que ubicar una piscina cubierta, para completar asi lo que se estimó como equipamiento deportivo mínimo para la Universidad Complutense. Campus de Somosaguas

En cuanto al equipamiento deportivo, cabe decir, que existe un proyecto complementario en el que se recoge la totalidad del material a disponer, incluidos los graderios móviles previstos citados anteriormente.

\section{Ficha técnica}

Situación : Campus de Somosaguas. Universidad Complutense de Madrid. Pozuelo de Alarcón - Madrid.

Fecha proyecto: abril 1993.

Fecha terminación: junio 1996

Arquitecto: Carlos García Tolosana

Colahoradores: Jumta de Obras U.C.M. D. Pedro Papic Fernández / Arquitecto. D. Antonio Letón Carrasco / Arquitecto. D. Ángel (jabriel Paraíso / Arquitecto Técnico

Aparejadores: D. Rafael de la Muela Mialdea. D. Luis Blázquez López

Promotores: UNIVERSIDAD COMPLUTENSE DE MADRD y CONSEJO SUPERIOR DE DEPORTES

Contratista: AUXINI, S.A.

Empresas colaboradoras: GEOCISA, EUROCONSULT Y ARKYGESTUR CONSULTORES S.A.

Presupuesto Ejecución Material: 300.000 .000 pts.

Superficie construida: $\quad 3.235,40 \mathrm{~m}^{2}$

Costo E.M.m² e: $93.000 \mathrm{pts}$

Financiación: UNIVERSIDAD COMPLUTENSE DE MADRID. CONSEJO SUPERIOR DE DEPORTES 